\title{
Correction to: Internet of Things Based Best Fruit Segregation and Taxonomy System for Smart Agriculture
}

\author{
Ganesh Khekare (D), Kapil Wankhade (D), Urvashi Dhanre (D), \\ and Bhushan Vidhale
}

\section{Correction to:}

Chapter 4 in: J. K. Verma et al. (eds.), IoT and Cloud Computing for Societal Good, EAI/Springer Innovations in Communication and Computing, https://doi.org/10.1007/978-3-030-73885-3_4

This chapter was inadvertently published with an incorrect affiliation for the first author, Ganesh Khekare, as G H Raisoni College of Engineering, Nagpur, India. Whereas it should be Parul University, Vadodara, India. This has now been corrected. 